\title{
Noncontiguous Multiple Spinal Tuberculosis
}

\author{
Sim Sai Tin ${ }^{1}$, Viroj Wiwanitkit ${ }^{2}$ \\ ${ }^{I}$ Medical Science, Medical Center, Shantou, China, ${ }^{2}$ Visiting Professor, Hainan Medical University, China
}

Dear Editor, we would like to discuss on the publication on "noncontiguous multiple spinal tuberculosis ${ }^{11}$." Kim et al. noted that "the disease should be considered in differential diagnosis along with other diseases such as metastatic neoplasm, pyogenic spondylitis, especially when the radiologic studies are revealing multiple spinal lesions ${ }^{1)}$ " As noted by Kim, "multi-level noncontiguous, remote vertebral tuberculosis" is not common and sometimes difficult to diagnose. To diagnose the case, the microbiological diagnosis is sometimes not available and presumptive diagnosis is used ${ }^{2}$. The use of antituberculosis drug is needed and surgery might be used in cases with "large abscess formation, severe kyphosis, an evolving neurological deficit, or lack of response to medical treatment ${ }^{3)}$." The challenge in the case with noncontiguous multiple spinal tuberculosis is the multiple level surgery. Based on the experience reported from Taiwan of China, it is noted that "decompression at all lesion levels" should be used in a patient with multiple-level compression symptom ${ }^{4)}$.

\section{REFERENCES}

1. Kim JH, Kim SH, Choi JI, Lim DJ: Atypical noncontiguous multiple spinal tuberculosis: a case report. Korean J Spine 11(2): 77-80, 2014

2. Joob B, Wiwanitkit V: Management of pyogenic discitis. Asian Spine J 8(3):391, 2014

3. Garg RK, Somvanshi DS: Spinal tuberculosis: a review. J Spinal Cord Med 34(5):440-54, 2011

4. Chen CF, Chang MC, Liu CL, Chen TH: Acute noncontiguous multiple-level thoracic disc herniations with myelopathy: a case report. Spine (Phila Pa 1976) 29(8):E157-60, 2004
- Received: September 5, 2014 - Revised: November 2, 2014

- Accepted: November 4, 2014

Corresponding Author: Sim Sai Tin, MD

Medical Center, Shantou, China

Tel: +866624132436, Fax: +866624132436

E-mail: simsaitin@gmail.com

®This is an Open Access article distributed under the terms of the Creative Commons Attribution Non-Commercial License (http://creativecommons.org/ licenses/by-nc/3.0/) which permits unrestricted non-commercial use, distribution, and reproduction in any medium, provided the original work is properly cited. 